\title{
Rodent and Human Trials of the Testosterone Modulating Experimental Nutraceutical Taxadrol
}

\section{Jeff Golini*}

All American Pharmaceutical and Natural Foods Corporation, Billings, Montana, USA

\begin{abstract}
Background: Testosterone therapy is commonly used by individuals dealing with testosterone deficiency (TD). TD affects older men and athletes with a history of anabolic steroid use. In this study a novel nutraceutical product, Taxadrol, was tested in rodents and human subjects to assess toxicity and activity as a testosterone therapy.

Materials: Taxadrol, consisting of a proprietary mixture of natural products, was tested for toxicity and efficacy in rodents and humans

Results: Rodents examined at 10,17, 24 and 7 days post withdrawal of Taxadrol were found to have increases in free and total testosterone compared to control animals when given 4 and $8 \mathrm{mg} / \mathrm{kg}$ doses. An average of $180 \%$ improvement in testosterone levels were also noted in two human subjects who ingested a $30 \mathrm{mg}$ per day dose of Taxadrol.

Conclusion: Increases in free and total testosterone were noted in rodent models with no signs of toxicity. Taxadrol was additionally shown to effectively raise testosterone levels in two male athletes with no major side effects.
\end{abstract}

Keywords: Testosterone; Hormone therapy; Nutraceutical

\section{Introduction}

Low testosterone levels or TD (testosterone deficiency) can lead to abnormalities in muscle and bone development, loss of vigor, energy and sexual drive along with low sperm count. In addition, testosterone deficiency can be seen in older men, athletes with a history of anabolic steroid use and others with androgen deficiency [1-3]. Currently, treatments offered for chronic low testosterone (also known as hypogonadism, androgen deficiency of the aging male and testosterone deficiency) are focused on testosterone replacement [4,5]. The goal of hormonal replacement is to return testosterone to "normal" levelsarguably above $400 \mathrm{ng} / \mathrm{dL}$, but the level of testosterone that causes symptoms of low testosterone fluctuates between individuals [4-6]. Treatment is normally initiated in patients whose low testosterone symptoms negatively impact their daily life, and treatment dosage is often determined by the alleviation of these symptoms [4-7].

The common treatment is supplemental testosterone, and the main difference in treatment is the mode of delivery, all of which have different side effects. These include testosterone injections, testosterone patch, testosterone gel (1\%), subcutaneous pellet and oral testosterone [4-6]. Other testosterone treatments under development include longer lasting forms of testosterone such as testosterone buciclate and testosterone undecanoate, as well as investigations into the potential clinical benefit of other, non-reducing androgens $[5,6]$.

Other options include agents such as clomiphene citrate and anastrozole, or gonadotropins replacement (hCG and hMG purified from female samples), both of which increase FSH and LH levels to stimulate production of testosterone in leydig cells as well as restoring spermatogenesis $[4,5]$. The main benefit of this therapy is that it also restores fertility, so individuals worried about having children increase their ability to do so [4]. Unfortunately, not every patient will recover normal testosterone with these therapies, which are intended as fertility treatments. Alternative therapies include "compound gels" made by pharmacies mixing testosterone with hand cream or lotion. Natural supplements containing subtheraputic levels of Viagra or dehydroepiandrosterone have been suggested to increase levels of testosterone, but they are not FDA regulated [4].

A novel proprietary nutraceutical mixture, Taxadrol, is considered that may act as an alternative to traditional hormone therapy in the treatment of TD. Preliminary studies in rodents and humans aimed at establishing toxicity and activity profile of this mixture are presented. Both the rodent model and human subjects experienced increases in testosterone after Taxadrol usage suggesting a potential utility in testosterone therapy.

\section{Materials and Methods}

\section{Taxadrol formulation}

Taxadrol consists of a unique proprietary mix of common Montana yew extract (Taxus baccata) tips, needles, bark, and branches, extracts of African yohimbe (Pausinystalia johimbe) bark and branches, and northwestern USA sarsaparilla (Smilax regelii) bark and branches. The extraction process incorporates a new advanced proprietary extraction/ isolation method developed by All American Pharmaceutical. Once the extraction and isolation process is finished, the material is then stabilized into an aqueous delivery system and administered at $30 \mathrm{mg}$ doses.

\section{Rodent study design and treatment}

Animal experiments were carried out in accordance to the

*Corresponding author: Jeff Golini, All American Pharmaceutical and Natura Foods Corporation, Billings, Montana, USA, Tel: (406) 245-5793; E-mail: jeffg@allamericanpharmaceutical.com

Received June 10, 2015; Accepted July 29, 2015; Published August 07, 2015

Citation: Golini J (2015) Rodent and Human Trials of the Testosterone Modulating Experimental Nutraceutical Taxadrol. J Biosens Bioelectron 6: 175. doi:10.4172/2155-6210.1000175

Copyright: (c) 2015 Golini J. This is an open-access article distributed under the terms of the Creative Commons Attribution License, which permits unrestricted use, distribution, and reproduction in any medium, provided the original author and source are credited. 
requirements of the European Convention for Protection of Vertebrate Animals used for Experimental and other Specific Purposes (1991). Six Wistar rats were given an oral dose of Taxadrol at $4 \mathrm{mg} / \mathrm{kg}, 20 \mathrm{mg} / \mathrm{kg}$, or none in addition to a normal diet. Each rat was fed the same type of food and provided free access to water.

Week 1- Weigh in of new rats and stabilization.

Week 2-5: Rats were weighed each morning and feed a normal chow diet along with the appropriate dose of Taxadrol. Observations were performed at 8:00 A.M., 12:00 P.M., 4:00 P.M. for sluggishness, bleeding, sores, tumors, alertness and skin temperature.

Week 6: Rats were examined for toxicity.

In follow-up, 160 healthy, pathogen free male Wistar rats were housed in a controlled environment: temperature $20-22^{\circ} \mathrm{C}$, free access to food and water as described above. The animals were randomly distributed in sixteen treatment groups consisted of 10 animals, as shown in Table 1. The oral treatment was carried out using a gastric tube. The animals were treated over 10,17, or 24 days, and sacrificed accordingly. Groups 8, 12 and 16 were sacrificed 7 days after the last treatment (together with control group 4) in order to assess the reversibility of the investigated pharmacological activity.

\section{Human study design}

Subjects were administered Taxadrol via oral administration

Week 1: $30 \mathrm{mg}$ once per day in the A.M.

Week 2-4: $30 \mathrm{mg}$ x twice per day A.M., P.M.

Week 5-7: $30 \mathrm{mg} x$ three times per day A.M., M.D., P.M.

Week 8: $30 \mathrm{mg}$ once per day A.M.

\section{Data processing and statistics}

The results from rat hormonal level investigations were statistically evaluated using a paired Student's t-test and post hoc Dunnet test, using BMD P4V, BMD P3D and BMD P7D software.

\section{Results}

\section{Rodent model}

An acute toxicity study was performed to assess the short-term

\begin{tabular}{|c|c|}
\hline S.No & Condition \\
\hline 1 & Untreated control (sacrificed on the $10^{\text {th }}$ day) (10 animals); \\
\hline 2 & Untreated control (sacrificed on the $17^{\text {th }}$ day) (10 animals); \\
\hline 3 & Untreated control (sacrificed on the $24^{\text {th }}$ day) (10 animals); \\
\hline 4 & Untreated control (sacrificed on the $31^{\text {th }}$ day) (10 animals); \\
\hline 5 & Taxadrol-treated (4 mg/kg, p.o., twice daily) (sacrificed on the $10^{\text {th }}$ day) (10 animals); \\
\hline 6 & Taxadrol-treated (4 mg/kg, p.o., twice daily) (sacrificed on the $17^{\text {th }}$ day) (10 animals); \\
\hline 7 & Taxadrol-treated (4 mg/kg, p.o., twice daily) (sacrificed on the $24^{\text {th }}$ day) (10 animals); \\
\hline 8 & Taxadrol-treated ( $4 \mathrm{mg} / \mathrm{kg}$, p.o., twice daily) (sacrificed on the $31^{\text {th }}$ day) (10 animals); \\
\hline 9 & Taxadrol-treated ( $8 \mathrm{mg} / \mathrm{kg}$, p.o., twice daily) (sacrificed on the $10^{\text {th }}$ day) ( 10 animals); \\
\hline 10 & Taxadrol-treated ( $8 \mathrm{mg} / \mathrm{kg}$, p.o., twice daily) (sacrificed on the $17^{\text {th }}$ day) ( 10 animals); \\
\hline 11 & Taxadrol-treated ( $8 \mathrm{mg} / \mathrm{kg}$, p.o., twice daily) (sacrificed on the $24^{\text {th }}$ day) ( 10 animals); \\
\hline 12 & Taxadrol-treated ( $8 \mathrm{mg} / \mathrm{kg}$, p.o., twice daily) (sacrificed on the $31^{\text {th }}$ day) (10 animals); \\
\hline 13 & Taxadrol-treated (16 mg/kg, p.o., twice daily) (sacrificed on the $10^{\text {th }}$ day) (10 animals); \\
\hline 14 & Taxadrol-treated (16 mg/kg, p.o., twice daily) (sacrificed on the $17^{\text {th }}$ day) (10 animals); \\
\hline 15 & Taxadrol-treated (16 mg/kg, p.o., twice daily) (sacrificed on the $24^{\text {th }}$ day) (10 animals); \\
\hline 16 & Taxadrol-treated (16 mg/kg, p.o., , twice daily) (sacrificed on the $31^{\text {th }}$ day) (10 animals); \\
\hline
\end{tabular}
Table 1: List of Rodent Treatment Conditions.

\begin{tabular}{|c|c|c|c|c|c|c|c|c|}
\hline \multirow{2}{*}{ Dose } & \multicolumn{2}{|c|}{$\begin{array}{c}10 \text { days } \\
\text { treatment }\end{array}$} & \multicolumn{2}{c|}{$\begin{array}{c}\text { 17 days } \\
\text { treatment }\end{array}$} & \multicolumn{2}{c|}{$\begin{array}{c}\text { 24 days } \\
\text { treatment }\end{array}$} & \multicolumn{2}{c|}{$\begin{array}{c}\text { 7 days post } \\
\text { treatment }\end{array}$} \\
\cline { 2 - 9 } & $\mathrm{ng} / \mathrm{ml}$ & $\%$ & $\mathrm{ng} / \mathrm{ml}$ & $\%$ & $\mathrm{ng} / \mathrm{ml}$ & $\%$ & $\mathrm{ng} / \mathrm{ml}$ & $\%$ \\
\hline Unit control & 0.95 & 100 & 1.12 & 100 & 1.06 & 100 & 1.18 & 100 \\
\hline $4 \mathrm{mg} / \mathrm{kg}$ bid & 1.05 & 110.3 & 1.05 & $93.4^{\text {N.S. }}$ & 0.78 & $73.5^{\text {N.S. }}$ & 1.31 & 110.9 \\
\hline $8 \mathrm{mg} / \mathrm{kg}$ bid & 1.14 & 199.9 & 1.49 & $132.2^{*}$ & 1.56 & $147.9^{\star}$ & 1.46 & $123.8^{*}$ \\
\hline $16 \mathrm{mg} / \mathrm{kg}$ bid & 1.14 & 120.4 & 1.3 & $115.6^{*}$ & 1.43 & $135.6^{*}$ & 1.43 & $121.8^{\text {N.S. }}$ \\
\hline
\end{tabular}

Each data point represents the arithmetic mean of values for 10 experimental animals; * $p<0.05$ vs. the untreated

Control (Students t-test); N.S. not significant vs. the untreated control $(p>0.05)$.

Table 2: Total testosterone levels in Taxadrol-treated vs. untreated male Wistar Rats.

\begin{tabular}{|c|c|c|c|c|c|c|}
\hline \multirow{2}{*}{ Dose } & \multicolumn{2}{|c|}{$\mathbf{1 7}$ days treatment } & \multicolumn{2}{|c|}{ 24 days treatment } & \multicolumn{2}{|c|}{ 7 days post treatment } \\
\cline { 2 - 7 } & $\mathrm{pg} / \mathrm{ml}$ & $\%$ & $\mathrm{pg} / \mathrm{ml}$ & $\%$ & $\mathrm{pg} / \mathrm{ml}$ & $\%$ \\
\hline Unit control & 8.67 & 100 & 10.55 & 100 & 12.40 & 100 \\
\hline $4 \mathrm{mg} / \mathrm{kg}$ bid & 8.55 & $98.6^{\text {N.S }}$ & 9.40 & $89.1^{\text {N.S. }}$ & 10.42 & $84.0^{\text {N.S. }}$ \\
\hline $8 \mathrm{mg} / \mathrm{kgbid}$ & 12.76 & $147.1^{\star}$ & 18.05 & $171.1^{\star}$ & 15.86 & $127.9^{*}$ \\
\hline $16 \mathrm{mg} / \mathrm{kg}$ bid & 10.24 & $118.0^{\text {N.S. }}$ & 13.58 & $128.7^{\star}$ & 13.96 & $112.6^{\text {N.S }}$ \\
\hline
\end{tabular}

Each data point represents the arithmetic mean of values for 10 experimental animals; ${ }^{*} p<0.05$ vs. the untreated

Control (Students t-test); N.S. not significant vs. the untreated control $(p>0.05)$.

Table 3: Free testosterone levels in Taxadrol-treated vs. untreated male Wistar Rats.

toxicity of Taxadrol in white male Wistar rats when administered an oral dose equivalent to a standard recommended human dose and at 5 times the recommended dose. The study was intended to provide information on the potential health hazards of the test article with respect to oral exposure. In this test, one group of 6 rats received Taxadrol at $4 \mathrm{mg} / \mathrm{kg}$, a second group of 6 rats received Taxadrol at 20 $\mathrm{mg} / \mathrm{kg}$ and the third group of 6 rats was used as a control. At the end of 6 weeks the rats of all groups presented with no visible toxicity as represented by examinations of body mass, sluggishness, bleeding, sores, tumors, alertness and skin temperature.

In a more extensive follow-up study, $160 \mathrm{Wistar}$ rats were tested using a similar dosing schedule and sacrificed at various time frames to establish more extensive potential toxicological effect, effect on testosterone, and reversibility of Taxadrol's effects (Table 1). The results from the investigation are given in Tables 2 and 3 and in Figures 1 and 2. Changes in the testosterone levels, after exposure to Taxadrol allowed for some conclusions regarding the clastogenic effect in rats.

\section{Testosterone level monitoring}

Animals were sacrificed and blood samples were collected via cardiac puncture, in which the serum fractions were isolated. The determination of testosterone levels was carried out in the Higher Institute of Veterinary Medicine (Sofia, Bulgaria), using commercially available kits. The blood samples from the animals sacrificed on the 10th day of the treatment period were assayed for total testosterone levels, whereas in all other treatment groups and controls the levels of both total and free testosterone were determined. After ten days, slightly elevated levels of total testosterone were observed which trended toward significance. After 17 days of treatment a prominent statistically significant change in total testosterone was observed in the 4 and $8 \mathrm{mg} / \mathrm{kg}$ groups. However, only the $8 \mathrm{mg} / \mathrm{kg}$ dosing model was statistically increased in free testosterone. At the end of the treatment period ( 24 days) these doses ( 4 and $8 \mathrm{mg} / \mathrm{kg}$ ) again proved to cause efficient increase in the total and free testosterone content, whereas 

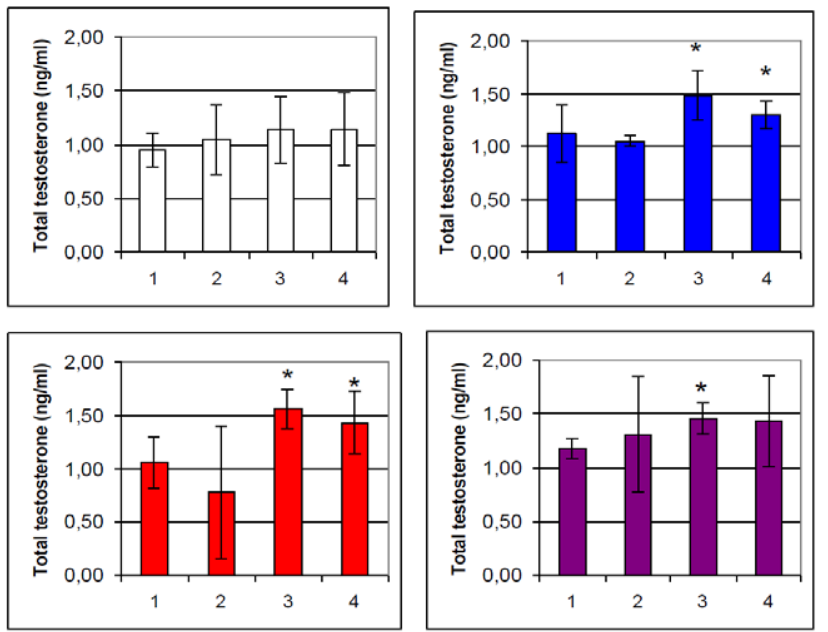

Figure 1: Total testosterone levels in Taxadrol@-treated vs untreated male Wistar rats after $10(\square), 17(\square)$ and $24(\square)$ days of treatment or 7 days post treatment $(\square)$. 1-Untreated control; 2-Taxadrol $₫(16 \mathrm{mg} / \mathrm{kg}$ bid); 3-Taxadro| $\circledast$ (8 $\mathrm{mg} / \mathrm{kg}$ bid); 4-Taxadrol® (4 mg/kg bid).
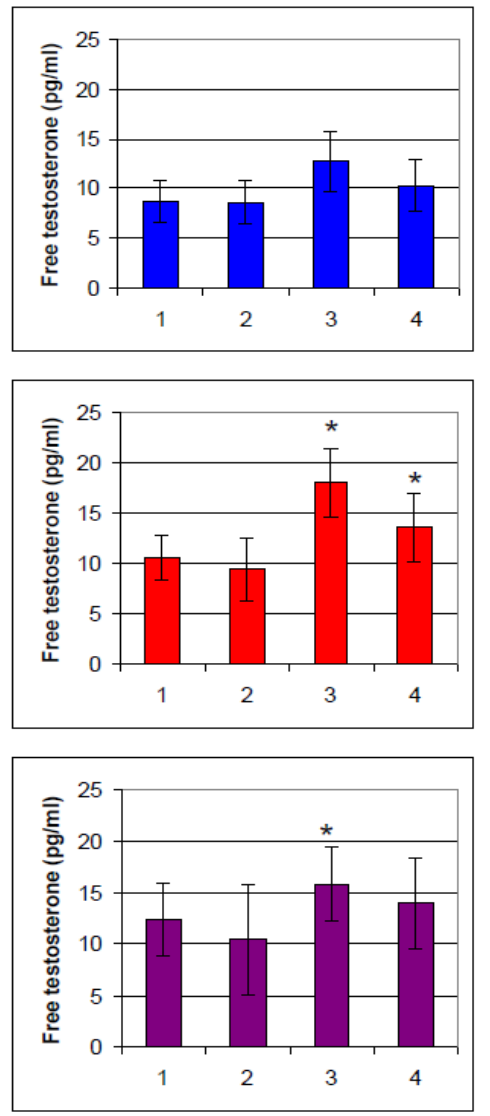

Figure 2: Free testosterone levels in Taxadrol $®$-treated vs. untreated male Wistar rats after $17(\square)$ and $24(\square)$ days of treatment or 7 days post treatment

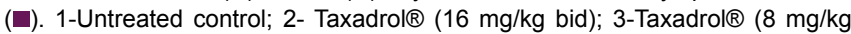
bid); 4-Taxadrol ${ }^{\circ}(4 \mathrm{mg} / \mathrm{kg} \mathrm{bid})$.

the highest dose $(16 \mathrm{mg} / \mathrm{kg})$ caused some decrease of the hormone concentration (though below significance).

\begin{tabular}{|l|c|c|c|c|}
\hline \multirow{2}{*}{} & \multicolumn{2}{|c|}{ Subject 1 } & \multicolumn{2}{c|}{ Subject 2 } \\
\cline { 2 - 5 } & pre & post & pre & post \\
\hline Serum Testosterone & $187 \mathrm{ng} / \mathrm{dl}$ & $755 \mathrm{ng} / \mathrm{dl}$ & $225 \mathrm{ng} / \mathrm{dl}$ & $400 \mathrm{ng} / \mathrm{dl}$ \\
\hline Serum Albumin & $4.2 \mathrm{~g} / \mathrm{dl}$ & $4.1 \mathrm{~g} / \mathrm{dl}$ & $4.0 \mathrm{~g} / \mathrm{dl}$ & $4.0 \mathrm{~g} / \mathrm{dl}$ \\
\hline C-Reactive Protein & $<0.8 \mathrm{mg} / \mathrm{L}$ & $<0.07 \mathrm{mg} / \mathrm{L}$ & $<0.7 \mathrm{mg} / \mathrm{L}$ & $<0.07 \mathrm{mg} / \mathrm{L}$ \\
\hline
\end{tabular}

Table 4: Increase in testosterone levels in human studies.

In addition, the established effects were sustained. Measured testosterone levels 7 days after the treatment cessation were increased in animals treated at a dose of $8 \mathrm{mg} / \mathrm{kg} / \mathrm{twice}$ daily in both free and total testosterone concentrations $v s$. the control group.

\section{Post-mortal evaluation}

Throughout the study period there was neither mortality nor alteration in the feeding behavior of treated animals as compared to the untreated controls. After collecting the blood samples the carcasses were necropsied by a qualified vet surgeon, and the visceral organs (liver, spleen, stomach, intestines) were examined for signs of toxicity. Moreover the animal body mass was monitored on regular basis as a non-specific marker of general toxicity. The post mortem examination of the visceral organs failed to reveal any signs of toxic deleterious effects in the treatment groups, as compared to the controls. Moreover the exposure of animals to Taxadrol caused no alterations in the weight gain rates of treated vs. untreated animals. Together these findings indicate that Taxadrol leads to a modest increase in testosterone levels in rodents and is devoid of general toxic effects.

\section{Human studies}

Two bodybuilders with low testosterone were chosen. Subjects were screened to make sure testosterone levels were low, that they were healthy and had not taken anabolic steroids. A questionnaire established the absence of anabolic steroids for a period of at least 4 years. Both men were over 40 years of age and were willing to go off all other supplements. Their workouts consisted of moderate training 5 days per week with cardio three days per week. No changes were made to their training schedule or diet.

Both subjects experienced increases in testosterone levels (Table 4). Both men improved in training intensity and strength. Increases in body weight and a noticeable decrease in body fat were reported. They further reported an increase in libido. No side effects were reported but a slight increase in aggressiveness, commonly seen with increased testosterone [8]. Serum Albumin and C-Reactive Protein was tested, as non-specific indicators of adverse events and inflammation [9], and found to be in a normal range with little to no change post Taxadrol exposure.

In a second trial, a retired male athlete with a history of performance enhancing substance use with low testosterone was chosen. Records provided to the testing coordinator, from this individual's doctor, revealed testosterone testing dating back to 2003. This body builder's testosterone levels during 2003 and 2006 ranged from 54 to 125 which required prescription testosterone therapy for health reasons. The therapy helped stabilize his testosterone levels. The total serum testosterone after therapy ranged from 100 to 125 to $\mathrm{ng} / \mathrm{dl}$.

Taxadrol was administered to the subject at dosages of $30 \mathrm{mg}$ per day taken sublingually. As noted, the testosterone serum level was125 $\mathrm{ng} / \mathrm{dl}$ measured on 9/21/06 while on testosterone therapy. The subject discontinued hormone therapy on $3 / 01 / 07$, and started on Taxadrol therapy on $4 / 30 / 07$. Testosterone serum levels with Taxadrol were $320 \mathrm{ng} / \mathrm{dl}$ on $9 / 13 / 07,333 \mathrm{ng} / \mathrm{dl}$ on $8 / 14 / 08,400 \mathrm{ng} / \mathrm{dl}$ on 9/14/09. 
The subject's serum testosterone levels increased from $125 \mathrm{ng} / \mathrm{dl}$ on traditional hormone therapy to $400 \mathrm{ng} / \mathrm{dl}$ on Taxadrol. Strength and size increases were reported along with decrease in body fat.

\section{Discussion}

Low testosterone levels or TD (testosterone deficiency) can lead to abnormalities in muscle and bone development, changes in vigor, energy, sexual drive and virility [10]. In this report animal studies were used to provide evidence against toxicity and for the use of the Taxadrol formulation in the regulation of human testosterone levels as a potential alternative to traditional hormone therapies. Human trials were intended to provide information on the potential health benefits and side effects of Taxadrol for athletes or any males suffering from low testosterone levels.

Prior to human studies, rat studies were performed to assess activity and toxicity. All rats examined remained active and showed no signs of sluggishness, bleeding, sores or tumors. All rats remained very alert and attentive during the study. No mortality occurred during the study. No clinical abnormalities were observed during the study. Body weight gain was noted for all animals during the test period. No significant gross internal or external findings were observed during the examination of the animals. The final examination also concluded that there were no microscopic lesions caused by the test article. Under the conditions of this test, all animals survived; therefore the oral toxicity must be $5 \mathrm{X}$ greater than the maximum administered human dose. Furthermore, convincing statistical evidence supports the finding that at recommended human doses, Taxadrol increases both total and free testosterone in rodents.

Following these trials, Taxadrol was shown to effectively raise testosterone levels in two male athletes by an average of 180\% with no major side effects. The athletes saw an increase in body mass with a reduction of body fat. They indicated additional qualitative improvements to training intensity but an increase in aggressiveness, also seen with traditional testosterone therapies [8]. In a second trial, Taxadrol raised a retired male athlete's testosterone levels dramatically over traditional hormone therapy. Although these trials are limited in scale they suggest that the efficacy of Taxadrol in humans is similar to that described in rodent models and suggests further study of this non- traditional therapeutic in correcting lowered testosterone in athletic males.

Despite these preliminary proof of principle results. Further analysis of the agent's efficacy and toxicological profile are required in humans. Specifically, a much larger cohort is required for statistical objectivity. Furthermore, examination of cardiovascular and liver markers commonly used as indicators of toxicity in testosterone therapy were not conducted. However, together with the rodent data, these preliminary findings are suggestive that this therapy might be used without overt toxic effects to participants.

\section{References}

1. Bhasin S, Cunningham GR, Hayes FJ, Matsumoto AM, Snyder PJ, et al (2010) Task Force ES: Testosterone therapy in men with androgen deficiency syndromes: An Endocrine Society clinical practice guideline. The Journal of clinical endocrinology and metabolism 95: 2536-2559.

2. Rahnema CD, Lipshultz LI, Crosnoe LE, Kovac JR, Kim ED (2014) Anabolic steroid-induced hypogonadism: Diagnosis and treatment. Fertility and sterility 101: 1271-1279.

3. Carson CC. Prevalence, diagnosis and treatment of Hypogonadism in Primary Care Practice.

4. Morgentaler A (2009) Testosterone for life: Recharge your vitality, sex drive muscle mass and overall health! McGraw-Hill, Harvard Medical School, New York.

5. Longo DL (2012) Harrison's principles of internal medicine, (18thedn), McGrawHill, New York,USA.

6. Surampudi P, Swerdloff RS, Wang C (2014) An update on male hypogonadism therapy. Expert opinion on pharmacotherapy 15: 1247-1264.

7. Tenover JL (2003) The androgen-deficient aging male: Current treatment options. Reviews in Urology 5: S 22-28.

8. Loomans MM, Tulen JHM, De Rijke YB, Van Marle HJ (2015) A hormonal approach to anti-social behaviour. Criminal behaviour and mental health $\mathrm{CBMH}$.

9. Iwata M, Kuzuya M, Kitagawa Y, Iguchi A (2006) Prognostic value of serum albumin combined with serum C-reactive protein levels in older hospitalized patients: Continuing importance of serum albumin. Aging clinical and experimental research 18: $307-311$

10. Golan R, Scovell JM, Ramasamy R (2015) Age-related testosterone decline is due to waning of both testicular and hypothalamic-pituitary function. The aging male, The official journal of the International Society for the Study of the Aging Male 15: 1-4. 